Rabaska

Revue d'ethnologie de l'Amérique française

\title{
Centre franco-ontarien de folklore
}

Patrick Breton

Volume 16, 2018

URI : https://id.erudit.org/iderudit/1051374ar

DOI : https://doi.org/10.7202/1051374ar

Aller au sommaire du numéro

Éditeur(s)

Société québécoise d'ethnologie

ISSN

1703-7433 (imprimé)

1916-7350 (numérique)

Découvrir la revue

Citer ce document

Breton, P. (2018). Centre franco-ontarien de folklore. Rabaska, 16, 351-352.

https://doi.org/10.7202/1051374ar

Ce document est protégé par la loi sur le droit d'auteur. L'utilisation des services d'Érudit (y compris la reproduction) est assujettie à sa politique d'utilisation que vous pouvez consulter en ligne.

https://apropos.erudit.org/fr/usagers/politique-dutilisation/
Cet article est diffusé et préservé par Érudit.

Érudit est un consortium interuniversitaire sans but lucratif composé de l'Université de Montréal, l'Université Laval et l'Université du Québec à Montréal. Il a pour mission la promotion et la valorisation de la recherche. https://www.erudit.org/fr/ 


\section{Ontario}

Centre franco-ontarien de folklore

Université de Sudbury

935, chemin du lac Ramsey

Sudbury (Ontatrio)

P3E 2C6
Téléphone : (705) 675-8986

Télécopieur : (705) 675-5809

Courriel : cfof@cfof.on.ca

Toile : www.cfof.on.ca

\section{Bilan de l'année 2017-2018}

Ce bilan se base sur les quatre axes de la planification stratégique 2017-2022 du Centre franco-ontarien de folklore (CFOF), soit la gouvernance, le rayonnement, la conservation et la programmation; il couvre la période du $1^{\text {er }}$ avril 2017 au 31 mars 2018.

\section{Gouvernance}

Nous avons tenu 10 réunions du conseil d'administration et une assemblée générale annuelle au cours de l'année, dont deux avec des présentations d'invités. Les membres du conseil d'administration proviennent de différentes régions de la province : Thunder-Bay, Sudbury, Pénétanguishene, Windsor, Woodstock, Ottawa et Québec. Nous avons présentement 105 membres. Le CFOF est membre du Regroupement des organismes culturels de Sudbury (Rocs) et l'un des sept partenaires du projet de Place des arts, un édifice de 30 millions \$ qui sera construit en 2020 pour abriter tous ces organismes.

\section{Rayonnement}

En plus des partenaires actuels (membres du Rocs, Conseils scolaires et Centre de santé communautaire du Grand Sudbury), nous avons établi un partenariat avec l'association Conteurs du Canada pour des émissions de radio diffusées sur internet et le programme de bourse pour les conteurs émergents. Nous avons participé au Festival de contes de Montréal ; nous avons aussi collaboré avec ce festival et avec celui de Trois-Pistoles pour la venue d'un conteur européen au Festival de contes de Sudbury. Nous travaillons depuis septembre dernier avec le Musée de la mémoire vivante de Saint-Jean-Port-Joli pour une exposition sur la chanson traditionnelle, intitulée « S'cusez-là », qui sera présentée en septembre 2018. La direction du CFOF est aussi membre du conseil d'administration du Réseau du patrimoine francoontarien, et il en assure la présidence par intérim depuis avril 2018.

En janvier 2018, la soirée de la Fête des rois a attiré plus de 200 personnes à Sudbury, et une soixantaine à Thunder-Bay, lieu où le CFof n'était pas encore allé tenir d'activité. Deux contes de la série Les Vieux m'ont conté ont été traduits en langue croate pour la revue littéraire et culturelle biannuelle Tema, publiée à Zagreb, une publication de plusieurs centaines de pages tirée à 500 exemplaires.

\section{Conservation}

Nous avons embauché un archiviste d'octobre 2016 à juin 2018 pour cataloguer et vérifier l'organisation des archives du CFOF, tant les archives institutionnelles, les 
archives du père Germain Lemieux, les documents d'archives, que les artéfacts et les 45 œuvres d'art de l'artiste Claire Guillemette-Lamirande que nous avons obtenues en avril 2016. À la fin de l'été, l'inventaire des artéfacts sera parachevé et la bibliothèque de consultation mise à jour.

\section{Programmation}

En mai 2018, nous avons organisé un cercle de conteurs et prévoyons offrir de la formation aux conteurs de la province lors du deuxième Festival de contes en octobre 2018. Nous lancerons alors un Cercle de conteurs franco-ontariens (objectif de planification stratégique). Nous souhaitons devenir ainsi un centre de référence pour contes et conteurs, et recruter de nouveaux membres. Mais, plus important encore, nos démarches permettront à cet art de reprendre du souffle afin que les conteurs et les histoires qu'on se raconte en famille poursuivent leur cours.

La Soirée de chansons à répondre, qui s'avère de plus en plus populaire, permet aussi de faire vivre et revivre cette tradition de chanter des chansons à répondre en famille. Cette soirée est organisée dans le cadre des célébrations de la Saint-Jean Baptiste de Sudbury, en collaboration avec les clubs d'âge d'or de la région. Nous planifions une deuxième Soirée de chansons à répondre et le deuxième Festival de contes de Sudbury ; ce dernier prendra officiellement le nom de Festival Les vieux m'ont conté.

Les diverses activités de notre programme ont connu du succès, comme on le voit par le nombre de personnes présentes : juin 2017 : Soirée de chansons à répondre (134 personnes) ; septembre : levée du drapeau franco-ontarien (60 personnes) ; octobre : $1^{\text {er }}$ Festival de contes (320 personnes) ; novembre : dîner de la SainteCatherine (60 personnes) ; janvier 2018 : célébrations de la fête des rois à Chelmsford (200) et Thunder-Bay (60) ; février : Souper du patrimoine (90) et remise du prix annuel du CFOF le Billochet du jongleur à Jean-Pierre Pichette. Nous avons encore appuyé le Manoir des pionniers, qui offre des services aux personnes âgées, à organiser des activités pendant l'année, dont une journée de la Saint-Jean-Baptiste.

Enfin, l'exposition muséale «Vie paysanne », conçue en collaboration avec la Ville du Grand Sudbury, a été inaugurée en mars 2017 ; on peut la visiter jusqu'en octobre 2018.

PATRICK BRETON

\section{Folklore et ethnologie}

Université de Sudbury

Sudbury (Ontario)

P3E 2C6
Téléphone : (705)673-5661

Télécopieur : (705) 673-4912

Courriel :dmoisa@usudbury.ca

Toile : www.usudbury.com

\section{Programme renouvelé}

Après plusieurs mois de suspension, le programme de Folklore et ethnologie de l'Université de Sudbury est à nouveau ouvert aux inscriptions. Dernier bastion de l'enseignement de l'ethnologie et du patrimoine ethnologique en français, au $1^{\text {er }}$ cycle, au Canada, ce programme commence à prendre de l'ampleur. De nombreux chan- 